Forthcoming in Axiomathes.

Yunus Prasetya

Universitas Pelita Harapan

\title{
Inference to the Best Explanation and van Fraassen's Contextual Theory of Explanation: Reply to Park
}

On multiple occasions, Seungbae Park (2017; 2019b) argues that Bas van Fraassen's rejection of inference to the best explanation (IBE) is problematic for his contextual theory of explanation. Park (2017) argues that since van Fraassen uses IBE to support the contextual theory, he is not entitled to believe that contextual theory is true. In addition, Park (2019b) argues that van Fraassen's rejection of IBE, together with the English view of rationality that he holds, jointly implies that his critics are rationally free to disbelieve his contextual theory. This paper provides a defense of van Fraassen's views Park's objections. ${ }^{1}$ In section one, I explore Park's (2017, 2019b) objections against the contextual theory, based on van Fraassen's English view of rationality and his rejection of IBE. In section two, I point out three weaknesses of Park's objections against van Fraassen. First, van Fraassen may be perfectly content to accept the implications that Park claims to follow from his views. Second, even if van Fraassen rejects IBE as an argument form, that does not mean he rejects all instances of IBE. Third, van Fraassen does not, in fact, use IBE to support his contextual theory.

1. Park's criticism of IBE and van Fraassen's contextual theory

Van Fraassen $(1980 ; 1989)$ does not accept IBE. He claims that it is not a compelling form of inference, that we are often unwilling to believe the best explanation for a set of 
data. On this basis, he claims that it is rational to disbelieve the truth of scientific theories that are supported by IBE.

Park (2017) takes issue with van Fraassen's views on IBE and his disbelief in scientific theories. According to Park (2017), if van Fraassen disbelieves scientific theories because they are supported by IBE, he should also disbelieve the contextual theory of explanation. After all, van Fraassen argues for the contextual theory using IBE, so Park argues. At most, Park claims, van Fraassen may believe that the contextual theory is empirically adequate, not that it is true. To do otherwise would be to "apply a double standard to his theory and his epistemic colleagues' theories" $(2017,61)$.

Park (2019b) provides an additional criticism for van Fraassen's rejection of IBE. Namely, that when taken together with the English view of rationality, which van Fraassen accepts, it implies that we are rational to disbelieve the contextual theory. What is the English view of rationality? It is a view to be contrasted to the Prussian view of rationality. According to the Prussian legal system, "everything is forbidden which is not explicitly permitted" (van Fraassen 1989, 171) Correspondingly, the Prussian view of rationality states that "what it is rational to believe is exactly what one is rationally compelled to believe" (ibid.). In contrast, according to the English legal system, "everything is permitted that is not explicitly forbidden" (ibid.) This corresponds to the English view of rationality, on which "what it is rational to believe includes anything that one is not rationally compelled to disbelieve" (ibid., 171-2). So, on van Fraassen's view, both belief that T is true and disbelief that $\mathrm{T}$ is true can be rational, as long as one is not rationally compelled to take either position. In fact, one is not compelled to take either position. This is because the belief that $\mathrm{T}$ is true is based on inference to the best explanation (IBE), which is not a compelling form of inference. Thus, belief that $\mathrm{T}$ is true is rational, but so is disbelief that $\mathrm{T}$ true. 
Now assume, for the sake of argument, that IBE is not rationally compelling and the English view of rationality is true. Park (2017; 2018a; 2019b) claims that van Fraassen (1980) uses IBE to support his contextual theory. But on van Fraassen's own views, this means that the support provided for the contextual theory is not compelling, which in turn means that we are rationally free to disbelieve it. Indeed, Park (2017) defends a view he develops, epistemic reciprocalism, on which "we ought to treat our epistemic colleagues in the way they treat their epistemic colleagues" (56). Given epistemic reciprocalism, Park argues, we should disbelieve van Fraassen's theories when it is rational to do so, because that is how van Fraassen treats his colleagues.

2. Three weaknesses of Park's objection against the contextual theory of explanation 2.1 First weakness: It is not disastrous if we can rationally disbelieve the contextual theory In this section, I point out three weaknesses of Park's criticisms. The first is that van Fraassen may happily affirm that it is reasonable to disbelieve the contextual theory, and that he only believes the contextual theory to be empirically adequate. Though, of course, he would likely not consider this implication as disastrous.

Let's start with belief that the contextual theory is empirically adequate. Park (2017) claims that there is a big difference between the truth of the contextual theory and the empirical adequacy of the theory.

The truth of the theory means that an explanation is an answer to a why-question, and that appropriateness of the answer depends on the context. The empirical adequacy of the theory, on the other hand, means that what it explains, viz. the phenomena, such as rejections and asymmetries, occur in scientific practices (61).

So, if van Fraassen only believes that the contextual theory is empirically adequate, he would not believe that an explanation is an answer to a why-question. 
This seems false. Van Fraassen does not define empirical adequacy in terms of explanation and belief in the empirical adequacy of a theory is not identical to belief in the phenomena that it explains. If we are to distinguish between empirical adequacy and truth for the contextual theory, we should be mindful of the fact that the distinction between empirical adequacy and truth applies primarily to scientific theories. The distinction does not translate well to non-scientific theories. This is because the distinction between truth and empirical adequacy depends on the distinction between observable and unobservable entities. A scientific theory is empirically adequate if what it says about observable things is true (van Fraassen 1980). As a corollary of this, if a theory only has observable entities as its postulates, then to believe that it is empirically adequate is just to believe that it is true.

We can now see the problem with using the concept of empirical adequacy to describe non-scientific theories. Scientific practices are not observable in the same sense that scientific phenomena are observable. We can, of course, reason that scientific phenomena are observable in an analogous sense of the term. However, why-questions and answers also seem observable in that analogous sense. After all, the asking and answering of why-questions seem just as obvious in scientific practice as rejections and asymmetries. If this is true, then belief in the empirical adequacy of the contextual theory involves believing that explanations are answers to why-questions, quite contrary to what Park claims.

If van Fraassen can only believe the empirical adequacy of the contextual theory, it is not because he cannot believe that an explanation is an answer to a why-question. Rather, it would be because, as Richard Healey (2019b) explains, van Fraassen defines a theory as a collection of models - a collection of abstract entities. However, this would amount to a different and much less disastrous implication of van Fraassen's views. If all we can criticize of van Fraassen's views is that he cannot believe in the abstract entities 
postulated by his positive theories, I think van Fraassen will be very happy. The exchange between, James Ladyman (2000; 2004) and Bradley Monton and van Fraassen (2003) is instructive on this point. Van Fraassen seems quite happy to claim that constructive empiricism fits better with realism about certain abstract entities.

What about the implication that van Fraassen's critics can rationally disbelieve the contextual theory? Again, this does not seem to be a disastrous consequence. After all, van Fraassen affirms similar implications to other aspects of his philosophy of science. For example, van Fraassen (1989) provides an extensive critique of laws. He argues that science is better off without laws. He admits, however, that belief in laws of nature is not irrational. He claims,

The great seventeenth-century writers on science, gave the concept of law a primafacie claim on our loyalties. The claim has not been borne out, the unanswered questions have proved unanswerable, the promises of explanatory gain even have proved empty, and the original insight has evaporated before us. The fact that belief in laws of nature is not ipso facto irrational does not ameliorate any of that. There is no significant sense in which 'anything goes' $(1989,182)$.

In this passage, van Fraassen suggests that you can have a rational belief that is defective in many other ways. Therefore, van Fraassen may happily affirm that it is rational to disbelieve the contextual theory. He would still be able to accuse his critics of other kinds of epistemic defects that arise from disbelieving the contextual theory. Thus, the implications that Park outlines seem much less disastrous than they may appear to be.

Park (2019a; 2020a) does provide reasons for thinking that the implication he draws from van Fraassen's views is disastrous. For one, he claims that we, as epistemic agents, aim "to propagate to others our own theories which we are confident about" (Park 2017, 58). However, Park (2019b) claims, if we accept the English view of rationality and reject IBE, we make this goal more difficult to achieve. In particular, van Fraassen will have a hard 
time trying to convince others to believe his contextual theory. Worse, van Fraassen may find himself in situations where it would be practically advantageous for him that others believe the contextual theory (Park 2018b; 2019a; 2020b). But those other people may appeal to the English view of rationality and the impotence of IBE to disbelieve his contextual theory.

I don't see how this puts van Fraassen in a disastrous situation. Even if we aim to convince others of the theories that we hold, that seems to be merely one among many goals that we have as epistemic agents. Other goals that we might also hold involve the attainment of understanding and wisdom (Kvanvig 2003; 2009), the attainment of justified belief and knowledge (Hawthorne 2004; Jones 2009), the ability to defend our theories from criticism and criticize others' theories that we find implausible (Park 2017), and so on. These other goals, however, may be better served by rejecting IBE and accepting the English view of rationality. So, even if van Fraassen's views make it difficult for him to attain one particular epistemic goal, they may be overall helpful to him in achieving these other epistemic goals.

Furthermore, rejecting IBE and accepting the English view of rationality does not leave us completely unable to propagate our theories. As illustrated in the passage quoted above from van Fraassen (1989), there are ways to convince others to adopt a belief without implying that it is irrational to do otherwise. Van Fraassen can use these methods to convince others to believe the contextual theory, whether it is to achieve his epistemic goals or to attain practical advantages.

I should point out that Park (2020a) argues that the debate between realists and antirealists should involve charges of irrationality from both sides. He claims that unless the antirealist claims that the realist holds irrational views, there can be no debate between them. "After all, it is irrational to criticize a reasonable position" (40). This is a 
very strong statement and it seems false. I think we offer criticisms for reasonable positions frequently, especially in the context of open inquiries. For example, before Copernicus, it was reasonable to hold a geocentric model of the universe. At that time, it was presumably also rational to criticize the geocentric model, to argue that the data calls for a different model. Only after criticisms of the geocentric model were accumulated and a better model was proposed did it become irrational to hold a geocentric model. ${ }^{2}$ So, there was a time when it was rational to believe the geocentric model and also rational to criticize the geocentric model.

2.2 Second weakness: Rejecting IBE does not mean rejecting all instances of IBE

Let's move to the second weakness. For now, we will suppose that Park is right in claiming that van Fraassen uses IBE to establish the truth of the contextual theory and that IBE is not compelling. It does not follow from this that therefore van Fraassen's argument for the contextual theory is not compelling. IBE is not a particular argument, but an argument form. Even if an argument form is unsafe, it does not follow that every instance of that argument form is unsafe. Take, for example, the fallacy of composition. An argument is an instance of the fallacy of composition if it has the following form.

(1) X is wholly composed of F's.

(2) Each of the F's that compose $\mathrm{X}$ is G.

(3) Therefore, $\mathrm{X}$ is $\mathrm{G}$.

We know that the inference from (1) and (2) to (3) is not safe. So, this argument form is not compelling. There are arguments that instantiate this form, have true premises, and false conclusions. That is all we mean when we claim that this is not a compelling argument form.

Now consider the following particular argument. 
(4) This unpainted wall is wholly composed of bricks.

(5) Each of the bricks that compose this wall is orange.

(6) Therefore, this unpainted wall is orange.

At a certain level of abstraction, this argument instantiates the form expressed in (1) to (3). In other words, it is an instance of the fallacy of composition. Yet it is a good argument.

Given what we know about walls, bricks, and the color orange, the conclusion of the argument follows from the premises. Indeed, when we do not abstract from it, is a valid argument because the inference from (4) and (5) to (6) is safe. If all the premises are true, the conclusion has to be true. ${ }^{3}$

But it seems contradictory to claim that an argument is safe despite instantiating an unsafe form. If an argument form is unsafe, doesn't it follow that every instantiation of it is unsafe ${ }^{4}$ We can resolve this apparent contradiction by noting that there are different levels of abstraction. At a certain level of abstraction, the argument in (4)-(6) instantiates the fallacy of composition. However, at a different level of abstraction, it instantiates the following form:

(7) Unpainted wall $W$ is wholly composed of bricks.

(8) Each of the bricks that compose $W$ is colored $C$.

(9) Therefore, $W$ is colored $C$

Unlike the fallacy of composition, the form expressed in (7)-(9) seems safe. So, despite instantiating the fallacy of composition, the argument in (4)-(6) is safe because it also instantiates the safe argument form expressed in (7)-(9).

Similarly, even if IBE is unsafe, a particular instance of IBE may be safe in virtue of instantiating a safe argument form at a different level of abstraction. Suppose, in a particular instance of IBE, the hypothesis under consideration is the best explanation because it is the only adequate explanation. Such an argument instantiates IBE, but it also 
instantiates inference to the only adequate explanation (IOAE). Douven \& Mirabile (2018) provide empirical evidence suggesting that ordinary epistemic agents infer the best explanation only when it is significantly better than the second-best explanation. Now suppose someone rejects IBE for this reason—sometimes, the best explanation is only slightly better than its rivals. Plausibly, this reason for rejecting IBE does not apply to IOAE, as the only adequate explanation is much better than its inadequate rivals. Such a person can accept a particular argument that instantiates IOAE, even though that argument also instantiates IBE. ${ }^{5}$

The lesson to learn is that we can endorse a particular argument as compelling without thereby endorsing all the forms that it instantiates. Likewise, we can reject an argument form without thereby rejecting every argument that instantiates that form. In this way, when van Fraassen criticizes IBE, he can still claim that certain arguments, which happen to be instances of IBE, are nevertheless compelling—for example, because they also instantiate IOAE. Indeed, van Fraassen leaves this as an open possibility. In criticizing IBE, van Fraassen claims,

[...] the verdict I shall urge is a gentle one. Someone who comes to hold a belief because he found it explanatory is not thereby irrational. He becomes irrational, however, if he adopts it as a rule to do so, and even more if he regards us as rationally compelled it. (van Fraassen 1989, 142)

Thus, van Fraassen claims that someone may rationally find particular instances of IBE compelling. His rejection of IBE only consists in the refusal to endorse IBE as a rule.

It is important to emphasize what I am not claiming. I am not agreeing with Park that van Fraassen's argument for the contextual theory instantiates IBE. Nor am I claiming that van Fraassen would defend or consider some arguments that have the form of IBE as compelling. I am merely claiming that even if van Fraassen's argument for the 
contextual theory instantiates IBE, he can claim that it is compelling. If he does, then he retains the ability to claim that those who disbelieve his contextual theory are irrational.

Park wishes to show that van Fraassen's rejection of IBE makes his argument for the contextual theory not compelling. Merely demonstrating that van Fraassen's argument for the contextual theory instantiates IBE is not enough. Park must also show that van Fraassen's argument for the contextual theory does not instantiate IOAE or some other safe argument form. As I'll argue in the next section, however, van Fraassen's argument for the contextual theory does instantiate (something like) IOAE.

2.3 van Fraassen does not use IBE to support the contextual theory.

The third weakness of Park's criticism is that van Fraassen does not, contrary to Park's claim, use IBE to support the contextual theory. Let's explore the evidence that Park provides for his claim that van Fraassen uses IBE to support the contextual theory. Park's (2017) provides the most extensive support for this claim as compared to his (2018a) and his (2019b). According to Park, van Fraassen claims that the correct theory of explanation must account for rejections of the demand for explanation and asymmetries in explanation. Van Fraassen also argues that his rival theories-Carl Hempel's (1965) deductive-nomological and inductive-statistical models, Wesley Salmon's (1971) statistical relevance model, and Michael Friedman's (1974) unificationist model—cannot do this. His contextual theory, on the other hand, can. Park then interprets this argument as IBE because "[van Fraassen] claims that his theory is true because it explains rejections and asymmetries whereas the aforementioned rival theories cannot" (Park 2017, 61). ${ }^{6}$

But note that Park is the one who describes the relationship between the contextual theory and rejections and asymmetries as explanatory. Van Fraassen does not use the term 
"explain" to describe the relationship between the contextual theory and rejections and asymmetries in explanation. Instead, he uses the terms "accommodate" and "account for."

Why is this important? Park $(2017 ; 2019 b)$ argues that van Fraassen should not be interpreted as claiming that the contextual theory is (merely) empirically adequate. He should, rather, be interpreted as claiming that the contextual theory is true. Park argues that van Fraassen does not describe the contextual theory as empirically adequate, but as correct. He then claims that since "empirically adequate" is a technical term, van Fraassen would likely not use a synonym in its place. So, when van Fraassen describes the contextual theory as correct, he means to say that it is true (Park 2019b).

But given this line of reasoning, we should also note that "explain" is a technical term for van Fraassen. When van Fraassen claims that something is explanatory, he means specifically that it is useful for answering why-questions. Thus, van Fraassen consistently distinguishes the explanatory power of a theory from its empirical strength. He suggests, on multiple occasions $(1977 ; 1980)$, that there is no epistemic value to explanation over and above the empirical strength of the theory used to explain. Additionally, van Fraassen (1989) states that IBE is distinct from Bayesian inferences. All of this suggests that when van Fraassen uses the term "explain," he means something very specific. If he means to claim that the contextual theory explains rejections and asymmetries, he would use the term "explain."

I suggest that van Fraassen's argument for the contextual theory should be interpreted in a different way. Van Fraassen (1985b) claims that his contextual theory is better than its rivals because "it succeeds more readily and simply in 'saving' these human phenomena" (641) of explanations. This means the contextual theory is not primarily appraised for explaining rejections and asymmetries. Rather, the contextual theory "saves" these phenomena. Van Fraassen notably uses the same phrase to describe the relationship 
between an empirically adequate theory and observable phenomena. He claims, "a theory is empirically adequate exactly if what it says about the observable things and events in this world, is true-exactly if it 'saves the phenomena"' (van Fraassen 1980, 12). So, the relationship between the contextual theory and the human phenomena of rejections and asymmetries is the same as that between an empirically adequate scientific theory and the observable parts of the world. As mentioned above, the distinction between empirical adequacy and truth does not translate well to non-scientific theories. But we may reason analogously. Scientific theories that save empirical phenomena are empirically adequate. So, what should we call theories that save non-empirical phenomena? Let's call them, simply, adequate.

Thus, I suggest the following interpretation of van Fraassen's argument. When he claims that a successful theory of explanation must "accommodate, and account for, both rejections and asymmetries," van Fraassen simply means that a theory of explanation must tell us what rejections and asymmetries are. The contextual theory does this. On the contextual theory, a rejection constitutes a denial of one of the presuppositions of a whyquestion. Asymmetries, on the other hand, arise from differences in the relevance relation, $\mathrm{R}$, of different why-question. In this way, van Fraassen is claiming that the contextual theory is adequate. In contrast, the rival theories are not adequate because they do not tell us what rejections and asymmetries are.

In summary, van Fraassen does not use IBE to support his contextual theory of explanation. He does not invoke explanatory virtues in support of his contextual theory. Rather, his argument for the contextual theory amounts to this.

(10) The contextual theory of explanation is adequate. It saves the phenomena.

(11) No other theory of explanation is adequate.

(12) So, the contextual theory is the only adequate theory of explanation.

(13) So, the contextual theory is true. 
The inference from (10) and (11) to (12) is compelling. If (10) and (11) are true, then (12) has to be true. What about the inference from (12) to (13)? I confess ignorance on this point. I am not certain whether van Fraassen would consider such an inference compelling. I have not found any textual evidence that would help us on this issue. But even if he does not consider this inference compelling, it simply prevents him from believing in the reality of models. It does not prevent him from believing that explanations are answers to whyquestions.

At any rate, the point remains that the inference from (12) to (13) is not IBE. The form of the inference is better described as an inference to the only adequate theory. It requires claiming that his theory is adequate and that there is no other adequate theory. ${ }^{7}$ So, the fact that van Fraassen considers IBE impotent is not relevant to whether we should consider his support for the contextual theory impotent.

\section{Conclusion}

I want to emphasize two points to conclude this paper. First, I don't claim that van Fraassen would endorse inference to the only adequate theory as compelling. He may not endorse it as a rule, in the same way that he does not endorse IBE as a rule. After all, it seems that in cases where the theory postulates few unobservable entities, the inference from empirical adequacy to truth is safer than in cases where the theory postulates many unobservable entities. Still, the fact that van Fraassen could endorse the inference from (9) to (10) and has not—-to my knowledge—-suggested otherwise is enough to dispel Park's criticism.

Second, Park (2017, 2019b) appeals to reciprocalism—-the principle that we ought to treat our epistemic colleagues the way they treat their epistemic colleagues-in his critique 
of van Fraassen. However, the weaknesses that I've pointed out in Park's argument have nothing to do with reciprocalism. The weaknesses of Park's arguments concern the application of the reciprocalist's principle, not the principle itself. Park has not, in fact, treated van Fraassen the way van Fraassen treats his epistemic colleagues. In this way, we can uphold reciprocalism as well as the importance of the social aspects of knowledge that motivate it (Goldman 1999). And we can do this while consistently expecting others to believe van Fraassen's contextual theory.

Notes

${ }^{1}$ Richard Healey (2019a; 2019b) has also provided criticisms of Park's objections against van Fraassen's views. Park has responded to these in his (2019a; 2020a). My objections, however, will have little to do with Healey's, though I will also take Park's responses to Healey into account as I raise my own objections. Also, the objection to van Fraassen's contextual theory is only part of Park's critique. Park also argues that van Fraassen leaves his critics free to rationally disbelieve the empirical adequacy of a theory that best explains the observed data. However, I will not be discussing this latter aspect of Park's criticism.

${ }^{2}$ In fact, van Fraassen (2002) provides an excellent account of rational change of opinion, which takes scientific revolutions as case studies. This seems relevant as scientific revolutions seem to involve a change of opinion from a one rational belief to another.

${ }^{3}$ Sure, you can stick a blue wallpaper on the wall, but that does not make the wall blue. The wall itself is still orange.

${ }^{4}$ I thank an anonymous reviewer for raising this objection. However, I think there are clear examples of good—indeed, valid—arguments that instantiate invalid forms of arguments. By definition, an argument is valid just in case it is impossible for all its premises to be true and its conclusion false. On this definition, any argument that has a tautologous conclusion is valid, even if 
only trivially. Thus, an argument that denies the antecedent but has a tautologous conclusion would be valid, even though it instantiates an invalid form.

${ }^{5}$ We may construe an argument form as picking out a set. For example, suppose IBE picks out the set of all arguments that instantiate IBE. Call it the "IBE set." When van Fraassen rejects IBE, he is only committed to claiming that some (perhaps many) members of the IBE set are unsafe. So, even if van Fraassen rejects IBE, he may affirm that some members of the IBE set are safe. He may also pick out a subset of the IBE set, such as the IOAE set, and claim that the IOAE set has, as its members, only safe members of the IBE set. Indeed, this seems to hold generally. Let us define inference to any statement (IAS) as the argument form that concludes any statement from any group of premises. We reject IAS. But that does not require claiming that every member of the IAS set is unsafe. After all, the Modus Ponens set is a subset of the IAS set.

${ }^{6}$ Healey (2019b) criticizes Park on this point, arguing that van Fraassen does not believe that the contextual theory is true, only that it is empirically adequate. Healey argues that on van Fraassen's view, a theory is a collection of models. But since van Fraassen does not believe that abstract entities (such as models) are real, he cannot believe that the contextual theory is true. Park (2019a) responds to this by providing textual evidence that suggest the contrary. On this point, I side with Park. I'd also like to add that James Ladyman $(2000 ; 2004)$ addressed a similar issue, arguing that the constructive empiricist is committed to modal realism. Monton and van Fraassen (2003) provides a response in which they partially concede that a constructive empiricist will find it easier to be a modal realist than a nominalist.

${ }^{7}$ None of these commit me to claiming that the contextual theory does not provide good explanations for rejections and asymmetries. In fact, van Fraassen claims that "the epistemic merits a theory may have or must have to figure in good explanations are not sui generis; they are just the merits it had in being empirically adequate" $(1980,88)$. In other words, by claiming that the contextual theory is adequate, van Fraassen, thereby, suggests that it may be useful for providing explanations. So, one cannot object to van Fraassen's argument by claiming that he does not consider the contextual theory to be explanatory. 


\section{References}

Douven, I., Mirabile, P. (2018) Best, second-best, and good-enough explanations: How they matter to reasoning. Journal of Experimental Psychology: Learning, Memory, and Cognition, 44, 1792-1813.

Friedman, M. (1974). Explanation and scientific understanding. Journal of Philosophy, 71(1), 5-19.

Goldman, A. (1999). Knowledge in a social world. Oxford University Press.

Hawthorne, J. (2004). Knowledge and lotteries. Oxford University Press.

Healey, R. (2019a). Four points in response to Seungbae Park. Social Epistemology Review and Reply Collective, 8(9), 43-45.

Healey, R. (2019b). The aims of reliable knowledge: Reply to Seungbae Park. Social Epistemology Review and Reply Collective, 8(9), 25-30.

Hempel, C. G. (1965). Aspects of scientific explanation. In Aspects of Scientific Explanation and Other Essays (pp. 331-496). Free Press.

Jones, W. E. (2009). The goods and the motivation of believing. In A. Haddock, A. Millar, \& D. Pritchard (Eds.), Epistemic value (pp. 139-162). Oxford University Press.

Kvanvig, J. (2003). The value of knowledge and the pursuit of understanding: Cambridge University Press.

Kvanvig, J. (2009). The value of understanding. In A. Haddock, A. Millar, \& D. Pritchard (Eds.), Epistemic value (pp. 95-112). Oxford University Press.

Ladyman, J. (2000). What's really wrong with constructive empiricism?: Van Fraassen and the metaphysics of modality. British Journal for the Philosophy of Science, 51(4), 837-856. 
Ladyman, J. (2004). Constructive empiricism and modal metaphysics: A reply to Monton and van Fraassen. British Journal for the Philosophy of Science, 55(4), 755-765.

Monton, B., \& van Fraassen, B. (2003). Constructive empiricism and modal nominalism. British Journal for the Philosophy of Science, 54(3), 405-422.

Park, S. (2017). Defense of epistemic reciprocalism. Filosofija. Sociologija, 28(1), 56-64.

Park, S. (2018a). In defense of the epistemic imperative. Axiomathes, 28(4), 435-446.

Park, S. (2018b). Philosophers and scientists are social epistemic agents. Social Epistemology Review and Reply Collective, 7(6), 31-43.

Park, S. (2019a). Constructive empiricism in a social world: Reply to Richard Healey. Social Epistemology Review and Reply Collective, 8(10), 146-154.

Park, S. (2019b). The disastrous implications of the "English" view of rationality in a social world. Social Epistemology, 33(1), 88-99.

Park, S. (2020a). Replies to Healey's comments regarding van Fraassen's positions. Social Epistemology Review and Reply Collective, 9(1), 38-47.

Park, S. (2020b). Scientific understanding, fictional understanding, and scientific progress. Journal for General Philosophy of Science, 51(1), 173-184.

Salmon, W. C. (1971). Statistical explanation. In W. C. Salmon, R. C. Jeffrey, \& J. G. Greeno, Statistical Explanation and Statistical Relevance (pp. 29-87). University of Pittsburgh Press.

van Fraassen, B. (1977). The pragmatics of explanation. American Philosophical Quarterly, 14(2), 143-150.

van Fraassen, B. (1980). The scientific image. Clarendon Press.

van Fraassen, B. (1985). Salmon on explanation. The Journal of Philosophy, 82(11), 639651.

van Fraassen, B. (1989). Laws and symmetry. Oxford University Press. 
van Fraassen, B. (2002). The empirical stance. Yale University Press. 